\title{
Health Effects of Dust Exposure on Respiratory Functions among Underground Mine Workers in the South African Gold Mining Industry
}

\author{
Article by Olukayode O. Alewi ${ }^{1}$, Ademola M. Amosu ${ }^{2}$, Ebenezer O.Daniel ${ }^{3}$ \\ ${ }^{I}$ Texila American University Guyana \\ ${ }^{2}$ Babcock University Ilishan-Remo Nigeria \\ ${ }^{3}$ Texila American University \\ E-mail:physiokay@yahoo.com
}

\begin{abstract}
Studies on the health effects of occupational exposure to dust on the respiratory function of the gold miners in Orkney gold minefields in South Africa are reportedly scarce.

This study was aimed at revealing the physiological effect(s) of exposure to dust, in the underground mine on respiratory functions such as the forced vital capacity $(F V C)$, the forced expiratory volume in one second (FEVI), and the peak expiratory flow (PEF); and compare this with non-miners.

A case-control study was conducted with the participants matched as close as possible. The gold miners were the case while the non-miners were the control.

The major instrument that was used to assess the respiratory function was the CONTEC SP1O digital spirometer. For the secondary effects, sphygmomanometer, digital weight scale, digital heart rate monitor were used.

Data Analysis was carried out using the Statistical Package for Social Sciences (SPSS) version 20 and the paired sample t-test.

There were statistically significant differences in all the 3 respiratory functions assessed between the gold miners and non-miners. The forced expiratory volume for the gold miners and non-gold miner are weakly and positively correlated $(r=0.289, p<0.000)$. There was a significant mean difference between the FVC for gold miners and non-gold miners in Orkney $(t 221=8.135, p<0.000)$ .Urgent steps at reducing the amount of occupational exposure to dust with possible resultant silicosis are needed to curb these observed variations.
\end{abstract}

Keywords: Dust exposure, respiratory functions, silicosis, underground mine workers.

\section{Introduction}

Dust has been recognized as the most serious occupational health hazard across South African Mining Industry. During the year 1998 alone more than 5600 mineworkers were certified with silicosis, a silica related lung disease (Labuschagne, 2006). While there have been many challenges in the gold mining industry particularly on safety and health issues as regards occupational exposure underground there has not been adequate study or research into the effects of dust on the respiratory function of these miners. Mining is been reported as the foundation of South Africa economy (Cmsa, 2014). One of the main hazards that confront miners the world over is occupational exposure to certain minerals found underground. They are also exposed to excessive underground heat, dust, noise, and poor ventilation. Millions of solid mineral miners face untimely mortality and various degrees of occupational illness and injuries secondary to this exposure. South Africa mainstay of the economy comes from the gold and platinum mines. Among miners generally, silica exposure is common though in variable proportions; and there is no decline in its prevalence between the years 1984 to 2009 (David et al, 2015).

Gold miners, in particular, are exposed to crystalline silica, asbestos, poor ventilation, noise, and dust while working underground resulting in impaired respiratory functions and respiratory diseases. Diseases like silicosis, asbestosis, and pulmonary tuberculosis common among gold miners who may be exposed to dust underground are given at least annual radiographic examination to check if they may have contracted silicosis (Gibbs,2002; MOSH, 2014 ). Patients with silicosis are more 
susceptible to tuberculosis infection known as silico-tuberculosis. With the abundant literature on silica and silicosis, it is surprising that little work has been done to compare this exposure and diseases (MOSH, 2014).

Cumulative silica exposure has to be relatively high to cause silicosis (Churchyard et al, 2004). In a study conducted among miners in America, cumulative exposure below $0.9 \mathrm{mg} / \mathrm{m} 3$-years did not result in silicosis (Churchyard et al, 2004). Therefore, the level of exposure has to be a little above $0.9 \mathrm{mg} / \mathrm{m} 3$ for silicosis to occur. It has been observed that $18.3-19.9 \%$ of gold miners in South Africa have silicosis according to a study (Churchyard et al, 2004). In spite of the large amount of underground gold mineral found in Orkney region, there is paucity of literature on the impact of occupational exposure to these minerals on the respiratory functions of miners in Orkney, South Africa. While we generally know the physiological effects of excessive heat and dehydration on the cardiorespiratory system, little is known about the cumulative effects of these on the respiratory function of gold miners in the Orkney region.

The aim of this study was to look at the effects of these exposures to underground minerals particularly to dust on the respiratory functions of the miners who work in Orkney, South Africa and comparing the same with their non-miners resident. The outcomes of interest in this study was primarily to look at the effects of these exposures on certain respiratory parameters like, the forced vital capacity (FVC), the forced expiratory volume in one second, (FEV1), and the forced expiratory flow in $25-75 \%$ of FVC using the digital spirometer as the primary instrument of measurement.

\section{Methodology}

\section{Research design}

A case-control study design was used. The gold miners were the case group, while the Orkney residents who are non-gold miners were taken as the control. These two groups were matched as close as possible in terms of age, gender, height, and race to limit the influence of these confounders on their respiratory indices. For example, the number of males in the case group and control group was similar, in terms of gender; both male and female were selected so also age was closely matched.

Sampling Technique

The Slovin's formula for calculating sample size was utilized while simple random sampling method was used to pick the participants.

The minimum sample size (n) using Slovin's formula: $\mathrm{n}=\mathrm{N} / 1+\mathrm{Ne}^{2}$, where $\mathrm{e}=0.05$, and target population, $\mathrm{N}=500$, giving $\mathrm{n}$ as 222 .

Participants, both miners, and non-miners were adequately matched on gender, height and age to limit extraneous influence on measurement (confounding factor). This is because of gender, age, and height influences respiratory function (Ostrowski \& Barud, 2006).

Ethical Consideration

Ethical clearance was obtained from the management of Duff Scott Hospital, Stilfontein after presentation of bonafide certificate from Texila American University. The participants were also made to sign a consent form before their participation.

\section{Data collection}

Data on demographics, cardiorespiratory parameters, and pulmonary function (FVC, FEV1, PEFR, and FEV1/FVC) were collected for both cases and control. Participants' maximal oxygen uptake, VO2max was calculated using the Uth-Sorenson-Overgaard-Pederson formulae: VO2max $=15^{*}$ (HRmax/HRrest) (Uth et al, 2005). During spirometry, it was ensured that all participants were screened for contraindications to spirometry which includes recent ophthalmic surgical procedure, pneumothorax, tight clothing, unstable angina, myocardial infarction and recent thoracoabdominal surgery. (ATS, 2005; ACOEM, 2000).

\section{Instrumentation}

1. Digital weighing scale.

2. Digital Sphygmomanometer.

3. A Spirometer (SP10 CONTEC). 
4. Height Meter. And 5. Pulse Oximeter.

\section{Data analysis}

Data analysis was done using the Statistical Package for Social Science (SPSS) version 20. Paired sample t-test was used to compare the mean differences between the gold miners and the non-gold miners. Distribution tables and figures like frequency table, pie and bar charts were used to represent measured variables. Statistical level of significance was set at $\mathrm{P}$-value $<0.05$.

Hypothesis

H0: There will be no significant difference in the respiratory functions of gold miners and non-gold miners.

H1: There will be a significant difference in the respiratory function of gold miners and non-gold miners.

\section{Results}

The results from the tables below showed that there was a significant difference in the respiratory functions of the gold miners and the non-miners in terms of their FEV1, FVC, and FEV1/FVC.

Table 1. FEV1/FVC of Gold Miners

\begin{tabular}{|l|l|l|l|l|l|}
\hline \multicolumn{2}{|c|}{} & Frequency & Percent & Valid Percent & $\begin{array}{l}\text { Cumulative } \\
\text { Percent }\end{array}$ \\
\hline \multirow{3}{*}{ Valid } & $\begin{array}{l}60-69 \text { [Abnormal; } \\
\text { Mild] }\end{array}$ & 3 & 1.4 & 1.4 & 1.4 \\
\cline { 2 - 6 } & $\begin{array}{l}70 \text { \& above [Normal] } \\
\text { Total }\end{array}$ & 219 & 98.6 & 98.6 & 100.0 \\
\cline { 2 - 7 } & 222 & 100.0 & 100.0 & \\
\hline
\end{tabular}

Table 2 below shows the FEV1/FVC of the non-miners.

Table 2. FEV1/FVC of non-miners

\begin{tabular}{|l|l|l|l|l|l|}
\hline \multicolumn{2}{|l|}{} & Frequency & Percent & $\begin{array}{l}\text { Valid } \\
\text { Percent }\end{array}$ & $\begin{array}{l}\text { Cumulative } \\
\text { Percent }\end{array}$ \\
\hline Valid & $\begin{array}{l}50-59 \\
\text { [Abnormal; } \\
\text { Moderate] }\end{array}$ & 1 & .5 & .5 & .5 \\
\cline { 2 - 6 } & $\begin{array}{l}\text { 60-69 } \\
\text { [Abnormal; } \\
\text { Mild] }\end{array}$ & 4 & 1.8 & 1.8 & 2.3 \\
\cline { 2 - 6 } & $\begin{array}{l}70 \& \text { above } \\
{[\text { Normal }]}\end{array}$ & 217 & 97.7 & 97.7 & 100.0 \\
\cline { 2 - 6 } & Total & 222 & 100.0 & 100.0 & \\
\hline
\end{tabular}

At statistical level of significance set at $\mathrm{P}$-value $<0.05$, the results shown in table 3 below concludes that the 3 indices of health measured (V02max, BMI, and HRmax/rest) were all significantly different.

Table 3. Paired sample test

\begin{tabular}{|c|c|c|c|c|c|c|c|c|c|}
\hline & \multicolumn{5}{|c|}{ Paired Differences } & \multirow[t]{3}{*}{$t$} & \multirow[t]{3}{*}{ df } & \multirow{3}{*}{$\begin{array}{l}\text { Sig. (2- } \\
\text { tailed) }\end{array}$} \\
\hline & & \multirow[t]{2}{*}{ Mean } & \multirow[t]{2}{*}{$\begin{array}{l}\text { Std. } \\
\text { Deviation }\end{array}$} & \multirow[t]{2}{*}{$\begin{array}{l}\text { Std. Error } \\
\text { Mean }\end{array}$} & \multicolumn{2}{|c|}{$\begin{array}{l}95 \% \text { Confidence } \\
\text { Interval of the } \\
\text { Difference }\end{array}$} & & & \\
\hline & & & & & Lower & Upper & & & \\
\hline $\begin{array}{l}\text { Pair } \\
1\end{array}$ & $\begin{array}{l}\text { VO2max - } \\
\text { VO2max OF } \\
\text { NON MINERS }\end{array}$ & 1.43919 & 5.18631 & .34808 & .75320 & 2.12517 & 4.135 & 221 & .000 \\
\hline
\end{tabular}


DOI: $10.21522 /$ TIJPH.2013.05.04.Art063

ISSN: $2520-3134$

\begin{tabular}{|l|l|l|l|l|l|l|l|l|l|}
\hline $\begin{array}{l}\text { Pair } \\
2\end{array}$ & $\begin{array}{l}\text { HRrest - HRrest } \\
\text { OF NON } \\
\text { MINERS }\end{array}$ & 1.60360 & 6.82195 & .45786 & -2.50593 & -.70127 & -3.502 & 221 & .001 \\
\hline $\begin{array}{l}\text { Pair } \\
3\end{array}$ & $\begin{array}{l}\text { HRmax - HRmax } \\
\text { OF NON } \\
\text { MINERS }\end{array}$ & 3.22523 & 14.34399 & .96271 & 1.32797 & 5.12248 & 3.350 & 221 & .001 \\
\hline $\begin{array}{l}\text { Pair } \\
4\end{array}$ & $\begin{array}{l}\text { BMI - BMI OF } \\
\text { NON MINERS }\end{array}$ & 1.16842 & 4.23916 & .28451 & -1.72913 & -.60772 & -4.107 & 221 & .000 \\
\hline
\end{tabular}

Table 4. Paired sample statistics

\begin{tabular}{|l|l|l|l|l|l|}
\hline \multicolumn{2}{|c|}{} & Mean & N & Std. Deviation & Std. Error Mean \\
\hline \multirow{2}{*}{ Pair 1 } & FEV1 & 2.8747 & 222 & .59405 & .03987 \\
\cline { 2 - 6 } & FEV1 OF NON MINERS & 3.2377 & 222 & .68208 & .04578 \\
\hline \multirow{2}{*}{ Pair 2 } & FVC & 3.3927 & 222 & .66832 & .04485 \\
\cline { 2 - 6 } & FVC OF NON MINERS & 3.8643 & 222 & .78791 & .05288 \\
\hline \multirow{2}{*}{ Pair 3 } & FEV1/FVC & .8456 & 222 & .04890 & .00328 \\
\cline { 2 - 6 } & $\begin{array}{l}\text { FEV1/FVC OF NON } \\
\text { MINERS }\end{array}$ & .8365 & 222 & .05709 & .00383 \\
\hline \multirow{2}{*}{ Pair 4 } & PEF & 5.8864 & 222 & 1.26549 & .08493 \\
\cline { 2 - 6 } & PEF OF NON MINERS & 6.3176 & 222 & 1.32372 & .08884 \\
\hline
\end{tabular}

Table 4 above shows the paired sample statistics showing statistically significant difference between the pair.

Table 5. Paired samples correlations

\begin{tabular}{|l|l|l|l|l|}
\hline \multicolumn{2}{|l|}{} & $\mathrm{N}$ & Correlation & Sig. \\
\hline Pair 1 & $\begin{array}{l}\text { FEV1 \& FEV1 OF NON } \\
\text { MINERS }\end{array}$ & 222 & .289 & .000 \\
\hline Pair 2 & $\begin{array}{l}\text { FVC \& FVC OF NON } \\
\text { MINERS }\end{array}$ & 222 & .305 & .000 \\
\hline Pair 3 & $\begin{array}{l}\text { FEV1/FVC \& FEV1/FVC } \\
\text { OF NON MINERS }\end{array}$ & 222 & -.015 & .827 \\
\hline Pair 4 & $\begin{array}{l}\text { PEF \& PEF OF NON } \\
\text { MINERS }\end{array}$ & 222 & .018 & .790 \\
\hline
\end{tabular}

The forced expiratory volume for the gold miners and non-gold miner are weakly and positively correlated $(r=0.289, \mathrm{p}<0.000)$ as seen in Table 5 above.

Table 6. Paired sample test

\begin{tabular}{|c|c|c|c|c|c|c|c|c|c|}
\hline & \multicolumn{5}{|c|}{ Paired Differences } & \multirow{3}{*}{1} & \multirow{3}{*}{ Df } & \multirow{3}{*}{$\begin{array}{l}\text { Sig. }(2 \\
\text { tailed })\end{array}$} \\
\hline & & \multirow[t]{2}{*}{ Mean } & \multirow[t]{2}{*}{$\begin{array}{l}\text { Std. } \\
\text { Deviatior }\end{array}$} & \multicolumn{3}{|c|}{\begin{tabular}{l|l} 
Std. Error & $95 \%$ Confidence Interval \\
Mean & of the Difference
\end{tabular}} & & & \\
\hline & & & & & Lower & Upper & & & \\
\hline $\begin{array}{l}\text { Pair } \\
1\end{array}$ & $\begin{array}{l}\text { FEV1 - FEV1 OF NON } \\
\text { MINERS }\end{array}$ & 36302 & .76418 & .05129 & -.46410 & -.26194 & 7.078 & 221 & .000 \\
\hline $\begin{array}{l}\text { Pair } \\
2\end{array}$ & $\begin{array}{l}\text { FVC - FVC OF NON } \\
\text { MINERS }\end{array}$ & .47162 & 86382 & .05798 & -.58588 & -.35736 & 8.135 & 221 & .000 \\
\hline $\begin{array}{l}\text { Pair } \\
3\end{array}$ & $\begin{array}{l}\text { FEV1/FVC - FEV1/FVC } \\
\text { OF NON MINERS }\end{array}$ & .00914 & .07571 & .00508 & -.00087 & .01916 & 1.799 & 221 & .073 \\
\hline $\begin{array}{l}\text { Pair } \\
4\end{array}$ & $\begin{array}{l}\text { PEF - PEF OF NON } \\
\text { MINERS }\end{array}$ & .43122 & 1.81482 & .12180 & -.67126 & -.19117 & 3.540 & 221 & .000 \\
\hline
\end{tabular}

The results as presented in Table 6 show that there is a significant difference between the

FEV1/FVC of gold miners in Orkney and that of non-gold miners in Orkney at the $10 \%$ significance 
level. The Sig. (2-Tailed) value for the FEV1/FVC is 0.073 . The FEV1/FVC for the gold miners and non-gold miner are weakly and negatively correlated $(r=-0.015, \mathrm{p}<0.073)$ as seen in table 6 above. There was a significant mean difference between the FEV1/FVC for gold miners and non-gold miners in Orkney at the $10 \%$ level of significance $(\mathrm{t} 221=1.799, \mathrm{p}<0.073)$ as seen in table 6 above. On average, the FEV1/FVC for the gold miners was 0.009 points lower than the FEV1/FVC for non-gold miners $(95 \%$ CI $[0.005,0.019])$ see Table 6 . The null hypothesis H0: There will be no significant difference in the respiratory functions of gold miners and non-gold miners are rejected.

\section{Discussion}

This study aimed to determine or evaluate the health effects of dust exposures on the respiratory function among underground mine workers in the South African. The result of this case-control study equally corroborated the early studies on the effects of dust exposure on miners (Labuschagne, 2006; Donoghue, 2004; William, 2007). The 3 health indices that compared the case with the controls that is the VO2max, HRrest/HRmax, and the BMI all show a statistically significant difference in the mean values of the miners and the non-miners. This signifies a better health in terms of maximal oxygen consumption, heart working rate, and basal metabolic index of the non-miner Orkney residents compared to the miners. The results as presented in Table 6 show that there is a significant difference between the FEV1 of gold miners in Orkney and that of non-gold miners in Orkney. The Sig. (2Tailed) value for the FEV1 is 0.000 . Since this value is less than 0.05 , we, therefore, conclude that there is a statistically significant difference between the mean FEV1 for the miners and non-miners in Orkney at the 5 percent level of significance. Since a decrease in the FEV1 value may mean the lung disease is getting worse, the mean number of forced expiratory volume (FEV1) for the miners are lesser than the mean for the non-miners, it can, therefore be concluded that non-miners are able to breathe and sleep significantly better that miners. Also, from the results there was a significant mean difference between the FEV1/FVC for gold miners and non-gold miners in Orkney at the $10 \%$ level of significance ( $\mathrm{t} 221=1.799, \mathrm{p}<0.073$ ) while on average, the FEV1/FVC for the gold miners were 0.009 points lower than the FEV1/FVC for non-gold miners (95\% CI [0.005, 0.019]) according to Table 6. It can, therefore, be concluded that the respiratory function or performance is significantly better among the non-miners compared to the gold-miners. This actually brings to the fore the essence of this study, which is to evaluate these pulmonary/respiratory function among the gold miners and non- miners that both reside in the same geographical area-Orkney. The only possible and reasonable explanation for these observed differences is associated with the occupational exposures particularly to dust found in the underground gold mines which the non-miners are not subjected to. Other occupational exposures by the gold miners to noise and heat could not have adversely affected their respiratory function and respiratory disease outcome as indicated by the questionnaire. In view of these findings more protective and, adequate measures become imperative to curb the negative health effects of this exposure to dust in the underground gold mines of Orkney and South Africa at large.

\section{Conclusion}

The result of the study which utilises three indices of health assessment, the VO2max; the HRrest and HRmax; and the basal metabolic index (BMI). The results as presented in the Table 3 show that there is a significant difference between the V02max of gold miners in Orkney and that of non-gold miners in Orkney. The Significant (2-Tailed) value for the V02max is 0.000. Since this value is less than 0.05 , we, therefore, conclude that there is a statistically significant difference between the mean V02max for the miners and non-miners in Orkney.

It was also revealed from the result that the HRrest and HRmax for the gold miners in Orkney area are statistically different from that of non-gold miners. The third health index, the BMI was also found to show a statistically significant difference between the mean BMI of gold miners and nonminers.

As revealed by the results of this study there was a statistically significant differences in the FEV1, FVC, and FEV1/FVC it can, therefore, be concluded, as all the three respiratory/pulmonary measures show statistically significant difference, that there is a significant difference between the respiratory function of gold miners and non-gold miners resident in Orkney area of South Africa. The null 
DOI: $10.21522 / \mathrm{TIJPH} .2013 .05 .04 . A r t 063$

ISSN: $2520-3134$

hypothesis is therefore rejected. A strong respiratory system is desirable and productive to these miners. (NIH, 2012). Gold mining activities, especially underground should be more regulated with enforcement of proper safety measures to limit the exposure. Adequate and well-structured occupational preventive measures (like adequate rehydration, fitting wears, air filter, etc.) become imperative in curbing these unnecessary adverse health outcomes. Public health practitioners should wade in to study and propose an adequate solution to this menace.

\section{References}

[1]. American College of Occupational and Environmental Medicine (2000). Spirometry in the occupational setting. J Occup Environ Med. 42:228-245.

[2]. American Thoracic Society/European Respiratory Society (2005). General considerations for lung function testing. Eur Respir J. 26:153-161. Available at: http://www.thoracic.org/statements/resources/pfet/PFT1.pdf.

[3]. Churchyard, G., Ehrlich, R., Naude, teWater, J., Pemba, L., Dekker, K., Vermeijs, M., \& Myers, J. (2004). Silicosis prevalence and exposure-response relations in South African goldminers. Occup Environ Med, 61(10), 811-816. Doi:10.1136/oem.2003.010967.

[4]. Cmsa Annual Report. (2013/2014). Chamber of Mines of South Africa. Cmsa-annual-report-2014.pdf.

[5]. David, K., Rodney, Ehrlich, Katherine, Fielding, Hannah, Jeffery, Alison, Grant, \& Gavin, Churchyard. (2015). Trends in silicosis prevalence and the healthy worker effect among gold miners in South Africa: a prevalence study with follow up of employment status. BMC Public Health, 15(1258). Doi: 10.1186/512889015-2566-8.

[6]. Donoghue, A.M. \& Bates, G.P. (2000). The risk of heat exhaustion at a deep underground metalliferous mine in relation to body-mass index and predicted Vo2max. Occup. Med, 50(4), 259-263. Retrieved from citeseerx.ist.psu.edu/viewdoc/download?

[7]. Gibbs, G.W., \& Du Toit R.S.J. (2002). Estimating the quartz exposure of South African gold miners. Ann Occup Hyg; 46(7):597-607. [PubMed].

[8]. Guide on Workers Health Protection. (2015). Retrieved from www.labour.gov.za/DOL/downloads/documents/useful-documents/occupational-health-and-safety/OHS_Silica Pamphlet.pdf.s.

[9]. Labuschagne, J. A (2006). Reported dust concentrations in underground gold mines over the year 1999 to 2002.

[10]. Mining Industry Occupational Safety \& Health. (2014). Retrieved from www.mosh.co.za.

[11]. NIOSH. (2000). Injuries, Illnesses, and Hazardous Exposures in the Mining Industry, 1986-1995. A surveillance Report. Washington DC.

[12]. Ostrowski, S., Barud, W. (2006). Factors Influencing Lung Function: Are The Predicted Values For Spirometry Reliable Enough? Journal of physiology and pharmacolog, 57(4), 263-271.

[13]. Pruthi, N., \& Multani, N.K. (2012). Influence of Age on Lung Function Tests. Journal of Exercise Science and Physiotherapy, 8(1). Retrieved from medind.nic.in/jau/t12/i1/jaut12i1pl.pdf.

[14]. The Respiratory System. NIH (2012). National Heart, Lung, and Blood Institute. Retrieved from https://www.nhlbi.nih.gov/health/health-topics/topics/hlw/system.

[15]. Uth, N., Sorenson, H., Overgaard, K., \& Pedersen, P.K. (2005). Estimation of VO2max from the ratio between HRmax and HRrest - the Heart Rate Ratio Method. Eur J Appl Physiol, 91(1). Retrieved from https://www.ncbi.nlm.nih.gov/pubmed/14624296.

[16]. William, N. R. (2007). Environmental and Occupational Medicine. 4th Ed. Philadelphia. Lippincolt Williams \& Wilkins. 